\title{
Front Matter: Volume 10839
}

, "Front Matter: Volume 10839," Proc. SPIE 10839, 9th International Symposium on Advanced Optical Manufacturing and Testing Technologies: Optical Test, Measurement Technology, and Equipment, 1083901 (18 January 2019); doi: $10.1117 / 12.2523486$ and Testing Technologies (AOMATT2018), 2018, Chengdu, China 


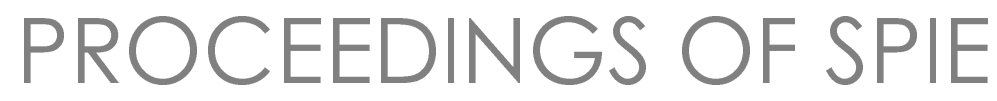

\title{
9th International Symposium on Advanced Optical Manufacturing and Testing Technologies \\ Optical Test, Measurement Technology, and Equipment
}

\author{
Fan Wu \\ Yudong Zhang \\ Xiaoliang Ma \\ Xiong Li \\ Bin Fan \\ Editors
}

26-29 June 2018

Chengdu, China

Organized by

Institute of Optics and Electronics, Chinese Academy of Sciences (China)

Sponsored by

COS-The Chinese Optical Society (China)

IOE-Institute of Optics and Electronics, Chinese Academy of Sciences (China)

Published by

SPIE

Volume 10839 
The papers in this volume were part of the technical conference cited on the cover and title page. Papers were selected and subject to review by the editors and conference program committee. Some conference presentations may not be available for publication. Additional papers and presentation recordings may be available online in the SPIE Digital Library at SPIEDigitalLibrary.org.

The papers reflect the work and thoughts of the authors and are published herein as submitted. The publisher is not responsible for the validity of the information or for any outcomes resulting from reliance thereon.

Please use the following format to cite material from these proceedings:

Author(s), "Title of Paper," in AOMATT 2018: Optical Test, Measurement Technology, and Equipment, edited by Fan Wu, Yudong Zhang, Xiaoliang Ma, Xiong Li, Bin Fan, Proceedings of SPIE Vol. 10839 (SPIE, Bellingham, WA, 2019) Seven-digit Article CID Number.

ISSN: 0277-786X

ISSN: 1996-756X (electronic)

ISBN: 9781510623200

ISBN: 9781510623217 (electronic)

Published by

SPIE

P.O. Box 10, Bellingham, Washington 98227-0010 USA

Telephone +1 3606763290 (Pacific Time) · Fax +1 3606471445

SPIE.org

Copyright (C) 2019, Society of Photo-Optical Instrumentation Engineers.

Copying of material in this book for internal or personal use, or for the internal or personal use of specific clients, beyond the fair use provisions granted by the U.S. Copyright Law is authorized by SPIE subject to payment of copying fees. The Transactional Reporting Service base fee for this volume is $\$ 18.00$ per article (or portion thereof), which should be paid directly to the Copyright Clearance Center (CCC), 222 Rosewood Drive, Danvers, MA 01923. Payment may also be made electronically through CCC Online at copyright.com. Other copying for republication, resale, advertising or promotion, or any form of systematic or multiple reproduction of any material in this book is prohibited except with permission in writing from the publisher. The CCC fee code is 0277$786 \mathrm{X} / 19 / \$ 18.00$.

Printed in the United States of America.

Publication of record for individual papers is online in the SPIE Digital Library.

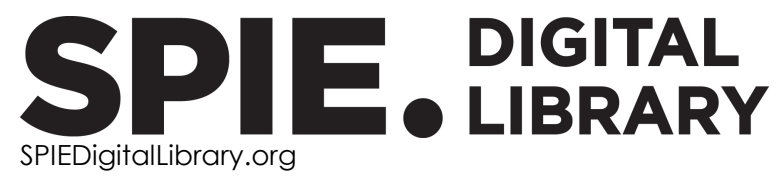

Paper Numbering: Proceedings of SPIE follow an e-First publication model. A unique citation identifier (CID) number is assigned to each article at the time of publication. Utilization of CIDs allows articles to be fully citable as soon as they are published online, and connects the same identifier to all online and print versions of the publication. SPIE uses a seven-digit CID article numbering system structured as follows:

- The first five digits correspond to the SPIE volume number.

- The last two digits indicate publication order within the volume using a Base 36 numbering system employing both numerals and letters. These two-number sets start with $00,01,02,03,04$, 05, 06, 07, 08, 09, OA, OB ... 0Z, followed by 10-1Z, 20-2Z, etc. The CID Number appears on each page of the manuscript. 


\title{
Contents
}

\author{
vii Authors \\ xi Symposium Committees \\ xiii AOMATT 2018 Sponsors
}

OPTICAL TEST, MEASUREMENT TECHNOLOGIES, AND EQUIPMENT

$1083902 \quad$ Feasibility study of scanning optical focusing detection system [10839-1]

$1083903 \quad$ Image tracking technology for dynamic angle measurement of machine vision [10839-2]

1083904 An accelerated ICP registration algorithm for 3D point cloud data [10839-3]

$1083905 \quad$ Feature extraction of three-point cloud images based on clustering analysis [10839-4]

1083906 A high precision field angle detection technology applied to laser communication system [10839-7]

$1083907 \quad$ Precision of the attitude algorithm of the strap-down inertial navigation system [10839-8]

1083908 Study on the calibration technique for multi-directional affine projection in optical computerized tomography [10839-9]

1083909 Real-time compensation of the time-skew and phase-mismatch for heterodyne DAS system [10839-10]

10839 OA Experiment on phase correction of reflection fringe based on camera calibration [10839-12]

10839 OB Research on reflection characteristics for a rectangular laser pulse passing through a FabryPerot interferometer [10839-13]

10839 OC The application of the digital filtering algorithms in the signal processing system of the microdisplacement sensor [10839-14]

10839 OD Research on photoelectric measurement method for filament diameter based on FPGA [10839-15]

$10839 \mathrm{OE} \quad$ The laser screen technology research of the firing dispersion and initial velocity test of the high shooting frequency weapons [10839-16] 
10839 OF Two methods comparison and verification for monochromator calibration of wavelength [10839-17]

10839 OG Optimal modified lateral shearing interferometer for in-line damage morphology measurement [10839-18]

$10839 \mathrm{OH} \quad$ Research and design of synchronous phase shifting optical profile detection system [10839-19]

$10839 \mathrm{Ol} \quad$ The design of motor vehicle exhaust carbon monoxide concentration detection system based on tunable diode laser absorption spectroscopy [10839-21]

10839 0J Study on the effects of multiple factors on the photoacoustic detection of glucose [10839-22]

10839 OK The theory model establishment and experiment measure of Lidar ranging signal in large incident angle condition [10839-23]

$10839 \mathrm{OL} \quad$ Application of variational mode decomposition method in Fourier transform profilometry [10839-24]

10839 OM A spectral calibration approach for snapshot Image Mapping Spectrometer (IMS) [10839-27]

10839 ON Analysis on uneven laser signal in laser guided weapon simulation [10839-28]

1083900 Develop the fiber coupling efficiency based on SPGD control algorithm [10839-30]

10839 OP Research on obstacle detection and location of indoor robot based on LIDAR [10839-31]

$10839 \mathrm{OQ}$ The comparisons between the preconditioned conjugate-gradient method and the Fourier transform method in lateral shearing interferometry [10839-35]

10839 OR The research on absolute distance measurement based on large-bandwidth reversesynchronous dynamic frequency scanning interference [10839-36]

10839 OS Design and Instrumentation of transmission digital holographic microscopy [10839-39]

10839 OT Improvement of specular gloss measurements in SIMT [10839-40]

10839 OU A digital filtering algorithm based on four-channel wavelet and its application in active optical system [10839-42]

10839 OV The studies of noninvasive blood glucose monitoring using optical coherence tomography [10839-44]

10839 OW Research on the UV energy measurement based on UV LEDs [10839-45]

$108390 \mathrm{X}$ The angular measurement of the motion direction of the stack motion platform based on the dual-frequency laser interferometer [10839-46]

10839 OY A research on the dynamic range of the dual channel monochrome sCMOS [10839-47] 
$10839 \mathrm{OZ}$ Optical axis parallelism calibration in three-channel filter-based non-imaging passive ranging system based on oxygen absorption [10839-48]

1083910 Study on irradiance metrology of single LED in comparison method [10839-49]

1083911 A device for comprehensive performance test of photoelectric system [10839-50]

1083912 Research on adaptive interferometric measurement of complex vibration environment [10839-53]

1083913 Study on spectral distribution and coherence length of light source [10839-56]

1083914 Optimized design of high-flux 2D magneto-optical trapping [10839-60]

1083915 Wavefront reconstruction in square region based on improved two-dimension Legendre polynomials [10839-63]

1083916 Study on image stitching algorithm of surface defects three-dimensional features measurement with transient interferometry [10839-64]

1083917 An improved feedforward controller design method [10839-65]

1083918 Fast measurement technique for obtaining the diffraction efficiency and its uniformity of a large-aperture pulse compression grating [10839-69]

1083919 Thin film thickness measurement based on laser heterodyne interferometry [10839-71]

10839 1A Refractive index gradient measurement method based on the principle of Mach-Zehnder interference [10839-74]

10839 1B Research on the software of the micro-displacement sensor in the active optical system based on FPGA [10839-76]

10839 1C Study of wavefront reconstruction based on four-wave lateral shear interferometer method [10839-80]

10839 ID Multi-wavelength investigation of the influence of polarization orientation on bulk damage resistance of type I doubler KDP crystals [10839-83]

10839 1E The combined application of two high speed cameras with different frequency in the study about explosion process [10839-84]

10839 IF A Mueller matrix measurement technique based on a division-of-aperture polarimetric camera [10839-85]

$108391 \mathrm{G} \quad$ Based on industrial inspection of the UV double-telecentric lens design [10839-88]

$108391 \mathrm{H} \quad$ Spatial location measurements of point target based on ultra-sparse image [10839-90] 
$1083911 \quad$ Research on key technology of the optical measurement device used in liquid oxygen tank of carrier rocket [10839-91]

$108391 \mathrm{~J} \quad$ Field registration and test for multi-module imaging spectrometer [10839-92]

$108391 \mathrm{~K} \quad$ Design of portable fundus camera system based on mobile phone [10839-96]

$108391 \mathrm{~L} \quad$ Detection of specular surface defects with eliminating dusts based on polarized structured-light illumination [10839-97]

$108391 \mathrm{M}$ Simulation prode of scanning optical focusing detection system design based on Zemax [10839-98]

10839 IN Study on calibration and error compensation of laser scanning system [10839-100]

1083910 Spectrum-analysis study of parameters associated with laser-induced air breakdown plasma [10839-101]

10839 IP Reconstruction of the free-falling body trajectory in an optical interferometric absolute gravimeter [10839-104]

$108391 Q \quad$ Mechanism design of a low temperature resistant and high precision zoom lens [10839-107]

10839 IR A novel optical system of fingerprint and finger vein images acquisition [10839-111]

10839 is Optical free form surface metrology in adaptive polarized interferometry [10839-113]

10839 1T Uncertainty analysis of dynamic goniometer based on fiber optic gyroscope [10839-115]

$108391 \mathrm{U} \quad$ Measurement for the structure of microcosmic defects on optical surface with digital holographic microscopy [10839-117]

10839 IV Comparison and analysis on the accurate measurement of spherical curvature radius [10839-1 18]

10839 IW The compact high energy DPSSL driving circuit system [10839-119]

10839 1X Glass viscoelasticity determination and analysis based on TMA compression creep [10839-124]

$108391 \mathrm{Y}$ An on-machine non-contact form measurement method for the high steepness elements [10839-130] 


\section{Authors}

Numbers in the index correspond to the last two digits of the seven-digit citation identifier (CID) article numbering system used in Proceedings of SPIE. The first five digits reflect the volume number. Base 36 numbering is employed for the last two digits and indicates the order of articles within the volume. Numbers start with 00, 01, 02, 03, 04, 05, 06, 07, 08, 09, OA, OB...0Z, followed by 10-12, 20-2Z, etc.

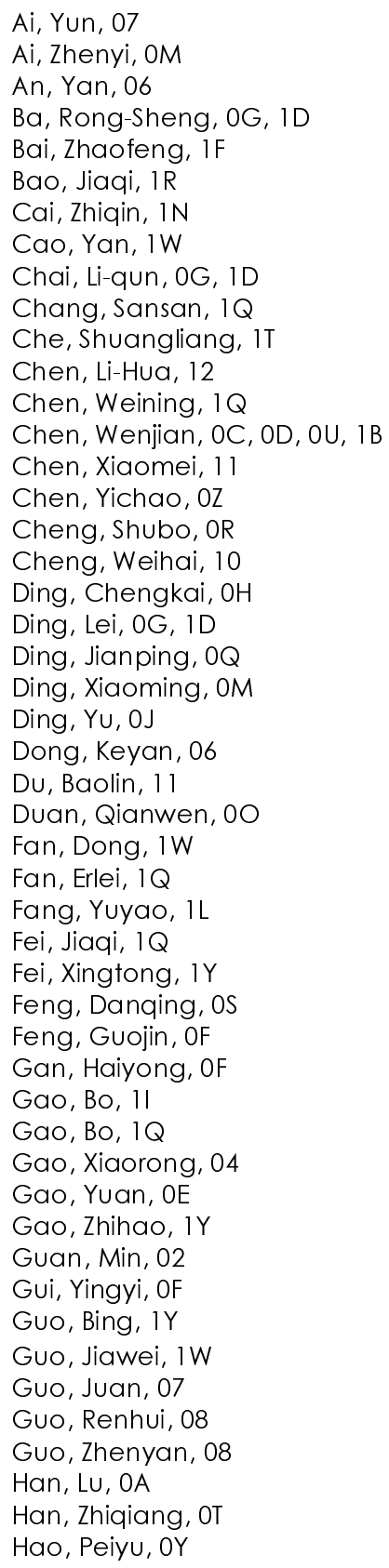

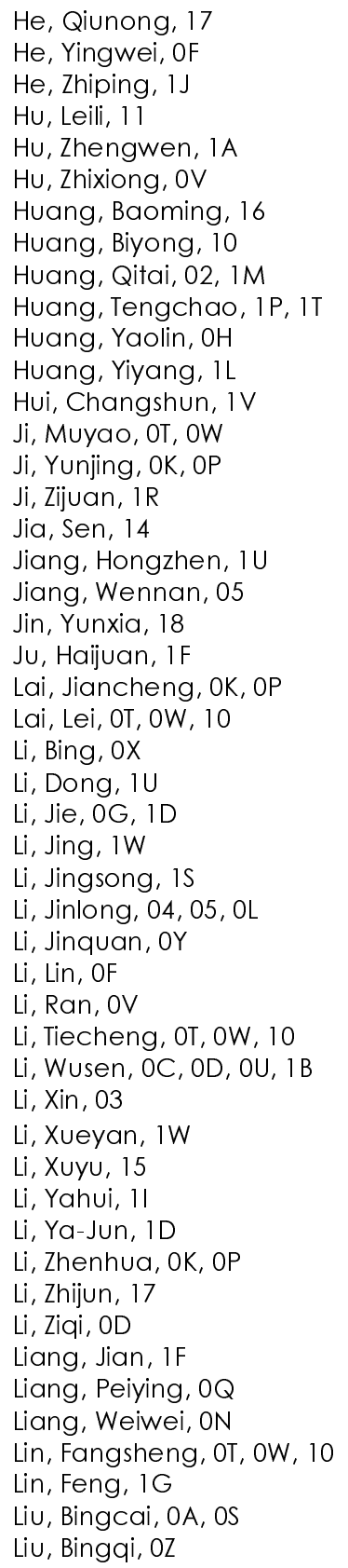


Liu, Changjiang, 11

Liu, Guodong, OJ

Liu, Guodong, OR

Liu, Guozhong, OV

Liu, Jidong, $1 \mathrm{H}$

Liu, Min, 12

Liu, Qiong, 00

Liu, Shijie, 16, 18

Liu, Tao, OV

Liu, Wen-qing, Ol

Liu, $X U, 1 \mathrm{U}$

Liu, Yong, $1 \mathrm{~L}$

Liu, Yong, $1 \mathrm{U}$

Liu, Zhilong, 1E

Lu, Chongyu, 09

Lu, Fei, $1 \mathrm{~K}$

Lu, Jie, $1 \mathrm{~N}$

Lu, Qing, 15

Lu, Yi-bing, Ol

Lu, Zengxiong, $\mathrm{OX}$

Luo, Hong, $1 \mathrm{X}$

LUo, Mingshi, OB

Ma, Kai, OY

Ma, Qinwei, $1 \mathrm{H}$

Ma, Shaopeng, $1 \mathrm{H}$

$M a$, Ying, $1 M$

Mao, Yao, 00, 17

Mei, Chao, 11

Meng, Jingan, 04

Mou, Jiapeng, 1P, $1 T$

$\mathrm{Na}$, Jin, 1D

$\mathrm{Ni}$, Kaizao, 16

Ning, Bai, OK

Pang, Bin, 1P, 1T

$\mathrm{Qi}$, Yongjun, OC, OU, 1B

Qi, Wei, OX

Qi, Yuejing, OX

Qiang, Zihao, 1I, 1Q

Qin, Kangzhi, OL

Qiu, Guangbo, OU

QU, Enshi, $1 F$

Ren, Huan, 1D

Ren, Liyong, $1 \mathrm{~F}$

Ren, Wei, $0 \mathrm{O}$

Ren, Zhong, 0J

Shang, Mingyang, 1A, $1 \mathrm{~K}$

Shao, Jianda, 15, 16, 18

Shao, Xiaoping, $\mathrm{OH}$

Shen, Yi, IV

Shi, Kai, 19

Shi, Kui, 07

Shi, Leibing, OT, OW

Shi, Zhan, OY

Shu, Xiaowu, 1P, 1T

Si, Minghua, 03

Song, Shiyi, $1 \mathrm{~N}$

Song, Wei, 14

Song, Yiping, $1 \mathrm{~L}$

Su, Jiani, OX
Su, Junhong, 1C, 10, 19

Su, Lijuan, OM

Sun, Xiaofei, 06

Tang, Xiao-dong, 1D

Tian, Ailing, OA, OS

Tian, Guobing, 1A, $1 \mathrm{~K}$

Wan, Wenbo, 1C

Wang, Changshi, OF

Wang, Chengge, IP

Wang, Chunyong, OK, OP

Wang, Guixia, 10

Wang, Hongjun, OA, OS

Wang, Jia, 08

Wang, Jianjun, $1 \mathrm{~N}$

Wang, Min, $\mathrm{OH}$

Wang, Peng, 1V

Wang, Qingsong, 10

Wang, Shanshan, 13

Wang, Shenghao, 18

Wang, Wanyue, $\mathrm{OM}$

Wang, Weiming, 03

Wang, Xianhua, 14

Wang, Xuanyu, $1 \mathrm{E}$

Wang, Yanbin, ON

Wang, Yu, OX

Wang, Yueming, 1J

Wang, Yuhua, $O Q$

Wang, Zeyong, 05

Wang, Zhenye, 06

Wang, Ziang, $\mathrm{OZ}$

Wang, Zinan, 09

Wei, Chaoyang, 15

Wu, Cuigang, 14

Wu, $\mathrm{HaO}, 03$

Wu, Li, 11

Wu, Shuiqin, 00

Wu, Xishan, OZ

Wu, Zhen, 15

Wu, Zhenyu, 1W

Xia, Xiaopeng, OV

Xia, Zhilin, 15, 18

Xie, Jia'nan, $1 \mathrm{~J}$

Xing, Chunlei, $1 \mathrm{~K}$

Xiong, Bangyun, $\mathrm{OQ}$

Xiong, Ji, 09

Xiong, Limin, OF

$X U$, Hong-Lei, 1D

$X U, D a, O E$

$X U$, Feng, $1 \mathrm{~A}, 1 \mathrm{~K}$

$X U$, Junqi, $1 O$

$X U$, Shichao, OB

$X U$, Xiaokang, 1B

$\mathrm{Xu}$, Yiyun, 06

Xue, Fanyan, $1 T$

Xue, Naitian, 09

Yan, Wei, OK, OP

Yan, Zongqun, $\mathrm{OZ}$ 
Yang, Feng, 1W

Yang, Guanghua, OX

Yang, Hongtao, $1 Q$

Yang, Jianhua, 1P

Yang, Kun, 1V

Yang, Lihong, 1C

Yang, Qiujie, $1 \mathrm{~J}$

Yao, Bin, 1N

Yao, Yujia, 1A, $1 \mathrm{~K}$

Yin, Dejin, OT, OW, 10

Yin, Ruiguang, ON

Yin, Shaohui, $1 X$

Ying, Guangyao, $1 T$

Yu, Benli, 15

Yu, Deqiang, $1 \mathrm{U}$

Yu, Dong-qi, Ol

Yu, Gan, OR

Yu, Hao, $\mathrm{OZ}$

YU, Kan, $1 R$

Yu, Yingjie, 16

Yuan, Jing, OG, 1D

Yuan, Liyin, 1J

Yuan, Yan, OM

Yue, Huimin, $1 \mathrm{~L}$

Zhang, Chao, 17

Zhang, Guangdong, 1Q

Zhang, Hao, $1 \mathrm{~V}$

Zhang, Junchao, OF

Zhang, Kai, Ol

Zhang, Lei, 1S

Zhang, LU, OB

Zhang, Sheng, $1 \mathrm{X}$

Zhang, Shuai, $\mathrm{OZ}$

Zhang, Wei, 07

Zhang, Yingying, 1X

Zhang, Yong, 03

Zhang, YU, OL

Zhang, $Y U, O Z$

Zhang, Yue, $1 Q$

Zhang, Yu-jun, Ol

Zhang, Zhi, 1Q

Zhang, Zhi-Hua, 12

Zhao, Caiqu, IW

Zhao, Qingliang, 1Y

Zhao, Siwei, OS

Zhao, Yue, 1Q

Zhao, Zhenyu, OY

Zhao, Zhi-Liang, 12

Zhao, Zi-Jia, 12

Zheng, Fanglan, $1 \mathrm{U}$

Zheng, Penglei, $1 \mathrm{~A}$

Zheng, Yin-Bo, OG, 1D

Zhou, Sheng, is

Zhou, Shuhong, 13

Zhou, Taogeng, OF

Zhou, Xi, 17

Zhou, Xin-Da, OG, 1D

Zhou, You, 16

Zhou, Zheng, $1 \mathrm{~L}$
Zhu, Haibin, $1 \mathrm{H}$

Zhu, Qiudong, 13

Zhu, Xueliang, OA, OS

Zhu, Yangqing, $\mathrm{OQ}$

Zhu, Yu, 18

Zhu, Yue, 08

Zhu, Zhen, $0 Q$

ZOU, Ailing, OP 
Proc. of SPIE Vol. 10839 1083901-10

Downloaded From: https://www.spiedigitallibrary.org/conference-proceedings-of-spie on 25 Apr 2023 Terms of Use: https://www.spiedigitallibrary.org/terms-of-use 


\section{Symposium Committees}

Symposium General Chairs

Bingkun Zhou, Tsinghua University (China)

Guangcan Guo, University of Science and Technology of China (China)

Liwei Zhou, Beijing Institute of Technology (China)

Qihuang Gong, Peking University (China)

Henri Lezec, National Institute of Standards and Technology (United States)

Minghui Hong, National University of Singapore (Singapore)

Yuwen Qin, National Natural Science Foundation of China (China)

Yudong Zhang, Chengdu Branch of Chinese Academy of Sciences (China)

Enhai Liu, Institute of Optics and Electronics (China)

International Advisory Committee

Wenhan Jiang, Institute of Optics and Electronics (China)

Yuen-Ron Shen, University of California, Berkeley (United States)

Myung K. Cho, National Optical Astronomy Observatory (United States)

Organizing Committee

Jinghua Cao, CAS Bureau of International Cooperation (China)

Yadong Jiang, University of Electronic Science and Technology of China (China)

Li Yang, Institute of Optics and Electronics (China)

Program Committee

Hu Yang, Institute of Optics and Electronics (China)

Xiaodi Tan, Beijing Institute of Technology (China)

Ting Xu, Nanjing University (China)

Qiao Xu, China Academy of Engineering Physics (China)

Xuanming Duan, Chongqing Institute of Green and Intelligent

Technology (China)

Xue Feng, Tsinghua University (China)

Junsheng Yu, University of Electronic Science and Technology of China (China)

Xinbin Cheng, Tongji University (China) 
Zheyu Fang, Peking University (China)

Rui Zhou, Xiamen University (China)

Changtao Wang, Institute of Optics and Electronics (China)

\section{Conference Chairs}

Yudong Zhang, Institute of Optics and Electronics (China)

Wei Gao, Tohoku University (Japan)

Min Xu, Fudan University (China) 


\title{
AOMATT 2018 SPONSORS
}

\author{
Organized by \\ Institute of Optics and Electronics, Chinese Academy of Sciences (China) \\ Sponsored by \\ COS-The Chinese Optical Society (China) \\ IOE-Institute of Optics and Electronics, Chinese Academy of Sciences \\ (China) \\ Technical Co-sponsor \\ SPIE \\ Supported by \\ Ministry of Science and Technology of China (China) \\ Chinese Academy of Sciences (China) \\ National Natural Science Foundation of China (China)
}


Proc. of SPIE Vol. 10839 1083901-14 Downloaded From: https://www.spiedigitallibrary.org/conference-proceedings-of-spie on 25 Apr 2023
Terms of Use: https://www.spiedigitallibrary.org/terms-of-use 